\title{
Prevalence of Peripheral Neuropathic Pain among Adult Diabetic Patients (T2DM) with Peripheral Neuropathy and Quality of Life of the Patients with Peripheral Neuropathic Pain
}

\author{
Jawad AHMAD Abu-Shennar ( $\square$ JAWAD_0799@YAHO0.COM ) \\ Near East University https://orcid.org/0000-0002-0505-5356 \\ Nurhan Bayraktar Bayraktar \\ Near East University \\ Hatice Bebis Bebis \\ Near East University
}

Research

Keywords: Diabetic peripheral neuropathic pain, Diabetes mellitus, Diabetic peripheral neuropathy, Quality of life

Posted Date: July 9th, 2020

DOI: https://doi.org/10.21203/rs.3.rs-40626/v1

License: (c) (1) This work is licensed under a Creative Commons Attribution 4.0 International License.

Read Full License 


\section{Abstract}

Aims: This study aims to assess the prevalence and characteristics of diabetic peripheral neuropathic pain (DPNP) among adult type 2 diabetes mellitus (T2DM) patients with diabetic peripheral neuropathy (DPN) and to determine the effects of DPNP on their quality of life (QoL).

Materials and methods: A cross-sectional study was conducted at the Jordanian Ministry of Health in Amman, Jordan during the period from the 15th of June 2019 to the 5th of October 2019. A total of 400 adult T2DM patients with DNP were recruited. Data were collected through a structured interview questionnaire and face- to- face interview. The DPNP was assessed using the translated version of Douleur Neuropathique4 (DN4), Besides, using the quality of life questionnaire entitled (EQ-5D) and Numeric Pain Rating Scale ( NRS ). Descriptive and inferential statistics were used for data analysis.

Results: The overall prevalence of DPNP based on DN4 was $47.8 \%$, more than half of the participants $50.3 \%$ were having mild pain, $45 \%$ were having moderate pain and $4.7 \%$ were having severe pain. The participants who have DPNP reported having problems in mobility, self-care, usual activity, and anxiety were reported in $(r=0.606)$ moderate $(50-69)$. Logistic regression analysis revealed that patients with an $\mathrm{HbA1c} \geq 7 \%$ were predictors to the increases/develop incidence of DPNP in adult T2DM patients with DPN.

Conclusion: The study showed a high prevalence of DPNP among adult T2DM patients with DPN. Early detection and intervention are important for DPNP patients. Moreover, efforts should be made by the health care provider to prevent the occurrence of DPNP using initial measures such as glycemic control.

\section{Introduction}

Type 2 diabetes mellitus (T2DM) is common and a serious chronic disease resulting from a complex inheritance-environment interaction along with other risk factors, for example, sedentary lifestyle and obesity. T2DM and its complications constitute a main worldwide public health problem, affecting people in both developed and developing countries with high rates of diabetes-related mortality and morbidity [1]. International Diabetic Federation in most recent estimates indicate that $8.3 \%$ (382 million people) have diabetes and the number of people with the disease is set to rise beyond 592 million $(10.1 \%)$ by 2035 with the greatest number between 40 to 59 years of age and $80 \%$ of them live in low and middleincome countries [2]. In Jordan, the prevalence of T2DM and impaired fasting glucose (IFG) were 17.1\% and $7.8 \%$ respectively [3]. While in the neighboring Arab countries, the prevalence of DM is increasing. In Kingdom of Saudi Arabia, the prevalence of DM was 30\% [4]; Saudi Arabia, Kuwait, and Qatar have 
ranked them into the top 10 (7th, 8 th \& 9th ) in the world with a prevalence of $24 \%, 23 \%$ and $23 \%$ respectively [2].

The cellular elements of the microvasculature appear to be most sensitive to injury from sustained hyperglycemia. This injury (and responses by the body directed toward its repair) causes organ/tissue dysfunction that affects the duration and quality of life for individuals with either type 1 diabetes mellitus (T1DM) or T2DM. Despite the disparate pathogenesis of these two common forms of diabetes, they (along with secondary forms of diabetes resulting from genetic mutations or pharmaceutical or surgical interventions) all share microvascular dysfunction/ injury as a chronic result [8]. Diabetic peripheral neuropathy (DPN) is defined as the presence of symptoms and/or signs of peripheral nerve dysfunction in people with diabetes after exclusion of other causes [5-7].

Diabetic peripheral neuropathic pain (DPNP) is an important problem among patients with DPN [9]. All over the world, many studies in Europe showed that the prevalence range from 40 to $50 \%$ [10]. Additionally, data from Cohort study among almost 7.5 million individuals contributing $38,118,838$ individual-years of observations in the UK, 6,779 new cases of DPNP were identified (45.5\%, females), giving an incidence rate of 17.8 per 100,000 individual-years. The incidence of DPNP increased with age, but it was stable over the three consecutive 3-year periods: $17.9,17.2$, and 18.4 cases per 100,000 individual-years. Of the 6,779 patients with incident DPNP, $15.5 \%$ had prior neuropathic screening during the study period in 2013 [15].

The American pain society (APS) defined DPNP as an unpleasant sensory and emotional experience associated with acute or potential tissue damage [14]. Diabetic peripheral neuropathic pain is characterized as burning, aching or shooting in nature. The pain usually interferes with daily living activities, mood, work, mobility, and social relations. The impaired health could have a negative impact on the patients' quality of life (QoL) and may cause in some cases sleep disruption and depression. Diabetic neuropathic pain causes higher societal and health care costs compared to diabetes without neuropathic pain [11]. As this condition progresses, the damage to peripheral nerves can be permanent, with loss of sensation leading to sores, ulcers, and, lower limb amputation [8, 12-13].

Effective management of DPNP is necessary to prevent the negative impact of the DPNP on the patients' QoL. Clinical practice guidelines for patients with diabetes recommended screening of all patients diagnosed with DM for neuropathy and a foot examination which includes annual checks for neuropathic symptoms, appropriate pain management, assessment of peripheral pulse and sensation to improve outcomes and the quality of life in those patients [1]. Moreover, as a positive association between DPNP and quality of life and patients with DPNP exists, it is recommended that all healthcare professionals should be knowledgeable of the importance of the quality of life and DPNP for those patients. Thus, early detection in primary care settings is necessary to increase awareness of the patients to initiate measures to prevent further complications, which may lead to improve planning and selecting the appropriate interventions [1]. 
Accordingly, this study aims to assess the prevalence and characteristics of DPNP among adult T2DM patients with DPN and to determine the effect it's on the patients' quality of life. To achieve these aims, the research will attempt to answer the following research questions:

- What is the prevalence of DPNP among adult patients(T2DM) with a DPN?

- What are the characteristics of DPNP among adult patients (T2DM) with a DPN?

- What are the effects of DPNP on the quality of life among those patients?

- Are there associated risk factors with increases/develop incidence of DPNP including sociodemographic, anthropometric measurements and clinical data in adult patients (T2DM) having a DPN?

\section{Methodology Study design}

A cross-sectional survey design was carried out on adult T2DM patients diagnosed with DPN. This design conducted at a period starting from ${ }^{15}$ th of June 2019 to the ${ }^{5}$ th of October 2019.

\section{Setting}

The study was conducted at the Jordanian Ministry of Health. The three hospitals are integrated under the name of the Jordan Ministry of Health. The researcher chose this setting because it receives referrals from all medical sectors in different parts of Jordan. It will be assumed that the selected setting would have a reflection of a patient with diabetes from different parts of Jordan. This center was established in 1921 Amman, Jordan with an annual admission rate of 25,000 patients of all disease that provides services to all patients from all around Jordan. Also, that provides screening services for each patient attending the Jordanian Ministry of Health center (clinics or hospitals), the services include following up of patients with diabetes mellitus every three months, in addition to routine measurements of blood glucose $\mathrm{HbA1c}$, blood pressure, weight, height, and waist circumference that are carried out in each visit. Every day, the medical records staff in each clinic picked up all the medical files of patients. They made them available on the nursing desk. Once the patients show up, they were received by a qualified nurse who performs some physical examinations that are needed for them before seeing their treating physician. Also, there are several specialized clinics in the center to deal with the complications of diabetes.

\section{Sampling And Sample Size}

The target population for this study was all adult T2DM patients with DPN who visited the Jordanian Ministry of Health, during the period from the ${ }^{15 \text { th }}$ of June 2019 to the ${ }^{5 \text { th }}$ of October 2019, and who are $\geq$ 
18 years of age having regular follow up in the hospitals for at least six months were included in the study.

Patients with the following conditions were excluded from the study as T1DM because those patients are beyond the purpose of this study. Besides, adult patients who underwent amputation of the whole foot, below the knee and above-knee amputations, were also excluded from the study because of the limited possibility to perform a physical examination on those patients. Also, the study does not examine any patient who didn't give verbal consent or respond to the questionnaire. The total sample size was 400 T2DM adult patients with DPN.

\section{Study Instrument}

An assessment tool package was used. This package consists of four parts. The first part was developed by the researchers and consisted of the demographic data, anthropometric measurement (last reading), laboratory measurement (last reading), type of treatment and type of diabetes that was obtained from the subjects who met the inclusion criteria.

The second part is an interview questionnaire Douleur Neuropathique4 DN4 (Bouhassira et al. 2005), the questioner diagnosis of DPNP among adult T2DM patients with DPN was made by a score of $\geq 3$. The DN4 score was derived by counting the number of positive responses to each of the first 7 items of the questionnaire, which includes burning sensation, painful cold sensation, electric shocks, tingling, pins and needles, numbness, itching, hypoesthesia to touch, hypoesthesia to prick, and brushing [16]. Only those who completed all 10 items of the DN4 questionnaire were included in the analysis for estimating the prevalence of DPNP, the responses to the questionnaire were either Yes or No. Also, Scores $\geq 3$ a sensitivity $89.9 \%$ were used in identifying patients with DPNP among adult T2DM patients with DPN while using a cut-off score point of 3 items out of 7 has a sensitivity $78 \%$ and specificity of $81.2 \%$ in identifying patients with DPNP [16]. This questionnaire was reported by the International Association for the Study of Pain in 2004 by (Bouhassira). The analysis of the psychometric properties of the DN4 questionnaire included: face validity, factor analysis and logistic regression to identify the discriminate properties of items or combinations of items for the diagnosis of neuropathic pain. The Arabian reliability and validity studies of the DN4 questionnaire was performed by Terkawi, A. S. et.al. in 2017, the results showed Arabic DN4 to have good diagnostic accuracy, with an area under the curve of 0.88 . As with the original version, a score of $\geq 4$ was found to be the best cut-off for the diagnosis of DPN, with a sensitivity of $88.31 \%$, the specificity of $74.47 \%$, a positive predictive value of $85 \%$, and a negative predictive value of $80 \%$. The Cronbach's alpha of the revised scale was 0.67 [17].

The third part is a physical exam; this is the second section from the DN4 questioner it includes hypoesthesia to touch, hypoesthesia to prick, and brushing [16]. The researcher was filled in each questionnaire using face to face interviews in the Arabic language. 
The fourth part is the quality of life questionnaire entitled EQ-5D [18]. This standardized instrument includes four domains that measure the QoL: mobility, self-care, usual activities, and anxiety/depression. The overall score was as 1: perfect health and 0: dead [18]. The EQ-5D has been translated by the researcher and checked by two professional academic instructors (Dr. Maysoon Abdalrahim and Dr. Ruqayya Zeilani) in the field of nursing to ensure the consistency of inquiring the information while interviewing the patients. The Jordanian reliability and validity studies of the EQ-5D was performed by Jawad Ahmad Abu-Shennar et.al. in 2020. The Cronbach's alpha of the revised scale was 0.88 [19].

In addition to the above measurements, the researcher measured the intensity of pain using the Numeric Pain Rating Scale (NRS). Each patient was asked to point to the number that represents the intensity of his current pain experience.

\section{Data Collection}

Data were collected with the following stages:

- Early on the day of the visit to the hospitals, excluding weekends (Fridays), the researcher made a list of adult T2DM participants' names with DPN and file numbers of those who meet the criteria of enrollment in the study.

- A face-to-face structured interview was made with the adult T2DM patients with DPN while waiting for his turn with the treating physician after finishing their laboratory check and nursing examination. Descriptive data were obtained and Douleur Neuropathique4 DN4 was implemented to evaluate DPNP. Each interview lasts for about 10 to 15 minutes.

- After the interviews, a physical examination for each participant was performed using the second section from the DN4 for evaluation of DPNP and patients with DPNP were determined.

- The intensity of pain was measured using the Numeric Pain Rating Scale (NRS) among the DPNP patients.

- Finally, the quality of life questionnaire entitled EQ-5D was collected among patients having DPNP.

\section{Statistical analysis}

Statistical analysis was carried out using the Statistical Package for Social Sciences (SPSS, version 25). Descriptive statistics obtained such as mean and stander deviation values for continuous and proportions for categorical variables. Chi-square was used to test the independent distribution of categorical variables where appropriate. Binary logistic regressions were used to examine the net effect for each of the proposed variables on DPNP. A P-value of less than 0.05 considered statistically significant.

\section{Ethical Consideration}


Data were collected after approval by the ethical committee in the Jordanian Ministry of Health. We have got approval from consultant specialist neurologist to apply of the DN4 as required of the Jordanian Ministry of Health ethical committee. The data was used only for scientific inquiries. Since the study was based on data obtained from medical records and structured questionnaires, no harm to the adult patients (T2DM) with DPN was expected. Verbal consent was taken by those eligible participate and they were assured about the confidentiality of information.

\section{Results}

In this cross-sectional study, the age of participants ranged from 30-88 years with a mean of 58.2 years $(S D= \pm 9.4)$. Around half of the participants were male $(87.5 \%)$, and the majority of them $(93.2 \%)$ were married. Also, $53.2 \%$ of the participants had never smoked whereas $33 \%$ were current smokers. Also, $37.2 \%$ had T2DM for less than five years, participants with diabetes between 5 to 11 years duration accounted for $32 \%$ with the mean duration of diabetes was of 9.7 years $(S D= \pm 7.3)$. (Table 1 ) shows further details of the socio-demographic characteristics of the participant. 
Table 1

Socio-demographic characteristics of the participants $n=$ 400

\begin{tabular}{|lll|}
\hline Participants' characteristics & $\mathbf{n}(\%)$ & Mean (SD) \\
\hline Age (year) & $56(14)$ & $58.2 \pm 9.4$ \\
$50-69$ & $291(72.8)$ \\
$\geq 70$ & $53(13.2)$ \\
\hline Gender & \\
Male & $350(87.5)$ \\
Female & $50(12.5)$ \\
\hline Marital status & \\
Single / Divorced /Widowed & $373(93.2)$ \\
Married & \\
\hline Working status & $49(12.2)$ \\
Unemployed & $172(43.0)$ \\
Employed & $179(44.8)$ \\
Retired & \\
\hline Level of Education & $140(35.0)$ \\
High school or less & $86(21.5)$ \\
Diploma college & $174(43.5)$ \\
Bachelor degree or higher & \\
\hline Medical insurance: & $23(5.8)$ \\
Have any insurance & $373(94.2)$ \\
Not insured & \\
\hline Smoking status & $231(53.2)$ \\
Not smoker & \\
Ex-smoker & \\
current smoker & \\
\hline
\end{tabular}




\begin{tabular}{|lll|}
\hline Participants' characteristics & $\mathbf{n}(\%)$ & Mean (SD) \\
\hline Duration of diabetes & $149(37.2)$ & $9.7 \pm 7.3$ \\
$<5$ years & $128(32.0)$ & \\
$5-11$ years & $123(30.8)$ & \\
$\geq 12$ years & & \\
\hline
\end{tabular}

Regarding the clinical and laboratory characteristics of the study participants (Table 2), the results showed that the mean BMI was $31.7 \mathrm{~kg} / \mathrm{m}^{2}(\mathrm{SD} \pm 5.4)$ more than half of the participants $59.2 \%$ were obese and $32.8 \%$ were overweight. Most of the participants were having comorbid diseases such as hypertension $85 \%$, dyslipidemia $87.8 \%$, cardiovascular disease $32.5 \%$, retinopathy $10 \%$, and nephropathy $5.5 \%$. Also, $65 \%$ of the participants had uncontrolled $\mathrm{HbA} 1 \mathrm{c}$ with the mean $\mathrm{HbA} 1 \mathrm{c}$ of $7.6 \%$ (SD \pm 1.5 ). Regarding the modality of treatment for T2DM $19.8 \%, 51.8 \%$, and $28.4 \%$ the study participants were on insulin only, oral hypoglycemic agents only, oral hypoglycemic agents with insulin and respectively. 
Table 2

Clinical and laboratory characteristic of the participants $n=400$

\begin{tabular}{|c|c|c|}
\hline Participants' characteristics & $\mathrm{n}(\%)$ & Mean (SD) \\
\hline Body mass index (BMI) $(\mathrm{Kg} / \mathrm{m} 2)$ * & $32(8.0)$ & $31.7 \pm 5.4$ \\
\hline Normal & $131(32.8)$ & \\
\hline Overweight & $237(59.2)$ & \\
\hline \multicolumn{3}{|l|}{ Obese } \\
\hline Comorbid diseases $\backslash$ conditions & $340(85.0)$ & \\
\hline Hypertension & $351(87.8)$ & \\
\hline Dyslipidemia & $40(10.0)$ & \\
\hline Retinopathy & $22(5.5)$ & \\
\hline Nephropathy & $130(32.5)$ & \\
\hline \multicolumn{3}{|l|}{ Cardiovascular diseases } \\
\hline Modality of treatment & $78(19.8)$ & \\
\hline Insulin only & $207(51.8)$ & \\
\hline Oral hypoglycemia agents only & $114(28.4)$ & \\
\hline \multicolumn{3}{|l|}{ Oral hypoglycemia agents \& Insulin } \\
\hline $\mathrm{HbA1C}(\%)$ & $140(35.0)$ & $7.6 \pm 1.5$ \\
\hline Controlled $<7 \%$ & $260(65.0)$ & \\
\hline \multicolumn{3}{|l|}{ Uncontrolled $\geq 7 \%$} \\
\hline *Normal: $18.5-24.9 \mathrm{~kg} / \mathrm{m}^{2}$, overwe & $9 \mathrm{~kg} / \mathrm{m}^{2}$ an & $\mathrm{se}: \geq 30 \mathrm{~kg} / \mathrm{m}$ \\
\hline
\end{tabular}

The researcher used the criteria based on the DN4 questionnaire which states that participants who obtained scores $\geq 3$ with at least one symptom are considered to have DPNP. Accordingly, the results of the study revealed that the overall prevalence of DPNP based on the DN4 questionnaire among adult T2DM patients with DPN $(n=400)$ was $47.8 \%(n=191)$ between the ${ }^{15 \text { th }}$ of June 2019 to the ${ }^{5 \text { th }}$ of October 2019.

Using the NRS measurement of pain intensity (Table 4), more than half of the participants $50.3 \%$ were having mild pain, $45 \%$ were having moderate pain and $4.7 \%$ were having severe pain. The most frequently reported symptoms were tingling $78.5 \%$, and burning $63.9 \%$, and the least reported symptoms were painful cold $15.7 \%$ and itching $16.2 \%$. presents the characteristics of pain in participants with DPN. 
Table 4

The intensity, nature of pain and quality of life in participants with DPNP ( $\mathrm{n}=$ 191).

\begin{tabular}{|c|c|c|}
\hline NRS scores & n (\%) & $\mathrm{P}$-value \\
\hline Mild pain $(\leq 3)$ & $96(50.3)$ & 0.000 \\
\hline Moderate pain (4-7) & $86(45.0)$ & \\
\hline Severe pain $(8-10)$ & $9(4.7)$ & \\
\hline Nature of DPNP* & $\mathrm{n}(\%)$ & \\
\hline Burning & $122(63.9)$ & 0.001 \\
\hline Painful cold & $30(15.7)$ & 0.004 \\
\hline Electric shocks & $38(19.9)$ & 0.000 \\
\hline Tingling & $150(78.5)$ & 0.000 \\
\hline Pins and needles & $104(54.5)$ & 0.000 \\
\hline Numbness & $83(43.5)$ & 0.000 \\
\hline Itching & $31(16.2)$ & 0.000 \\
\hline Quality of life & $\mathrm{n}(\%)$ & \\
\hline Mobility & $189(99)$ & 0.577 \\
\hline I have no problem in walking about & $1(0.5)$ & \\
\hline $\begin{array}{l}\text { I have severe problems in walking about } \\
\text { I am unable to walkout }\end{array}$ & $1(0.5)$ & \\
\hline Self-care & $186(97.4)$ & 0.472 \\
\hline I have no problems washing or dressing myself & $3(1.6)$ & \\
\hline I have slight problems washing or dressing myself & $1(0.5)$ & \\
\hline $\begin{array}{l}\text { I have severe problems washing or dressing myself } \\
\text { I am unable to wash or dress myself }\end{array}$ & $1(0.5)$ & \\
\hline Usual activities & $134(70.2)$ & 0.000 \\
\hline I have no problems doing my usual activity & $47(24.6)$ & \\
\hline I have slight problems doing my usual activity & $8(4.2)$ & \\
\hline $\begin{array}{l}\text { I have moderate problems doing my usual activity } \\
\text { I have severe problems doing my usual activity }\end{array}$ & $2(1.0)$ & \\
\hline
\end{tabular}




\begin{tabular}{|lll|}
\hline NRS scores & $\mathbf{n}(\%)$ & P-value \\
\hline Discomfort & $5(2.6)$ & 0.000 \\
I have no pain or discomfort & $83(43.5)$ & \\
I have slight pain or discomfort & $84(44)$ & \\
I have moderate pain or discomfort & $15(7.9)$ & \\
I have severe pain or discomfort & $4(2.1)$ & \\
I have extreme pain or discomfort & & \\
\hline Anxiety /Depression & $99(51.8)$ & 0.000 \\
I am not anxious or depressed & $70(36.6)$ & \\
I am slightly anxious or depressed & $19(9.9)$ & \\
I am moderately anxious or depressed & $3(1.6)$ & \\
I am severely anxious or depressed & \\
\hline *a patient may have more than four characters of pain & \\
\hline
\end{tabular}

Table 3 shows that the duration of diabetes $36.1 \%$ of the participant who is having diabetes longer than 12 years are having pain, $31.4 \%$ of patients with a duration between $5-11$ years were having pain and $32.5 \%$ of patients with diabetes of fewer than 5 years duration were having pain and this difference was found significant statistically $(P<0.05)$. Also, results showed that the pain was present in $71.2 \%$ of the patients with uncontrolled diabetes mellitus and $28.8 \%$ in the patients with controlled diabetes mellitus, and this difference was found significant statistically $(P<0.05)$. Besides, the pain was present in $30.4 \%$ and $60.7 \%$ in overweight and obese participants respectively, and this difference was found significant statistically $(P<0.05)$. 
Table 3

Relationship between DPNP and the selected socio-demographic and clinical data of the participants $n=400$

\begin{tabular}{|c|c|c|c|}
\hline Variables & $\begin{array}{l}\text { Pain } \\
\begin{array}{l}N=191 \\
n(\%)\end{array}\end{array}$ & $\begin{array}{l}\text { Without pain } \\
\mathrm{N}=209 \\
\mathrm{n}(\%)\end{array}$ & P-value* \\
\hline $\begin{array}{l}\text { Gender } \\
\text { Male } \\
\text { Female }\end{array}$ & $\begin{array}{l}171(89.5) \\
20(10.5)\end{array}$ & $\begin{array}{l}179(85.6) \\
30(14.4)\end{array}$ & 0.241 \\
\hline $\begin{array}{l}\text { Age } \\
<50 \\
50-69 \\
\geq 70\end{array}$ & $\begin{array}{l}25(13.1) \\
141(73.8) \\
25(13.1)\end{array}$ & $\begin{array}{l}31(14.8) \\
150(71.8) \\
28(13.4)\end{array}$ & 0.869 \\
\hline $\begin{array}{l}\text { Employment } \\
\text { Not employed } \\
\text { Employed } \\
\text { Retired }\end{array}$ & $\begin{array}{l}26(13.6) \\
74(38.7) \\
91(47.6)\end{array}$ & $\begin{array}{l}23(11.0) \\
98(46.9) \\
88(42.1)\end{array}$ & 0.249 \\
\hline $\begin{array}{l}\text { Smoking status } \\
\text { Not smoker } \\
\text { Ex-smoker } \\
\text { Current smoker }\end{array}$ & $\begin{array}{l}98(51.3) \\
26(13.6) \\
67(35.1)\end{array}$ & $\begin{array}{l}115(55.0) \\
29(13.9) \\
65(31.1)\end{array}$ & 0.690 \\
\hline $\begin{array}{l}\text { Body mass index (BMI) }(\mathrm{Kg} / \mathrm{m} 2) * \\
\text { Normal } \\
\text { Overweight } \\
\text { Obese }\end{array}$ & $\begin{array}{l}17(8.6) \\
58(30.4) \\
116(60.7)\end{array}$ & $\begin{array}{l}15(7.2) \\
73(34.9) \\
121(57.9)\end{array}$ & 0.565 \\
\hline $\begin{array}{l}\text { Duration of diabetes } \\
<5 \text { years } \\
5-11 \text { years } \\
\geq 12 \text { years }\end{array}$ & $\begin{array}{l}62(32.5) \\
60(31.4) \\
69(36.1)\end{array}$ & $\begin{array}{l}87(41.6) \\
68(32.5) \\
54(25.8)\end{array}$ & 0.057 \\
\hline
\end{tabular}

**Normal: $18.5-24.9 \mathrm{~kg} / \mathrm{m}^{2}$, overweight: $25-29.9 \mathrm{~kg} / \mathrm{m}^{2}$ and obese: $\geq 30 \mathrm{~kg} / \mathrm{m}^{2}$. 


\begin{tabular}{|llll|}
\hline Variables & Pain & Without pain & P-value* \\
& $\mathbf{N}=191$ & $\mathbf{N}=\mathbf{2 0 9}$ & \\
& $\mathbf{n}(\%)$ & $\mathbf{n}(\%)$ & \\
\hline HbA1c & $55(28.8)$ & $85(40.7)$ & 0.013 \\
Controlled $<7 \%$ & $136(71.2)$ & $124(59.3)$ & \\
Uncontrolled $\geq 7 \%$ & & & \\
Marital status & $16(8.4)$ & $11(5.3)$ & 0.215 \\
Single / Divorced / Widowed & $175(91.6)$ & $198(94.7)$ & \\
Married & & & \\
Level of Education & $72(37.7)$ & $68(32.5)$ & 0.184 \\
high school or less than & $45(23.6)$ & $41(19.6)$ & \\
Diploma collage & $74(38.7)$ & $100(47.8)$ & \\
Bachelor degree or higher & & & \\
\hline
\end{tabular}

**Normal: $18.5-24.9 \mathrm{~kg} / \mathrm{m}^{2}$, overweight: $25-29.9 \mathrm{~kg} / \mathrm{m}^{2}$ and obese: $\geq 30 \mathrm{~kg} / \mathrm{m}^{2}$. 


\begin{tabular}{|c|c|c|c|}
\hline Variables & $\begin{array}{l}\text { Pain } \\
\mathrm{N}=191 \\
\mathrm{n}(\%)\end{array}$ & $\begin{array}{l}\text { Without pain } \\
N=209 \\
n(\%)\end{array}$ & P-value* \\
\hline Comorbid diseases $\backslash$ conditions & $169(88.5)$ & $171(81.8)$ & 0.062 \\
\hline Hypertension & $22(11.5)$ & $38(18.2)$ & 0.048 \\
\hline Yes & $15(7.9)$ & $7(3.3)$ & 0.139 \\
\hline No & $176(92.1)$ & $202(96.7)$ & 0.670 \\
\hline Nephropathy & $69(36.1)$ & $61(29.2)$ & 0.049 \\
\hline Yes & $122(63.9)$ & $148(70.8)$ & \\
\hline No & $169(88.5)$ & $182(87.1)$ & \\
\hline Cardiovascular disease & $22(11.5)$ & $27(12.9)$ & \\
\hline Yes & $25(13.1)$ & $15(7.2)$ & \\
\hline No & $166(86.9)$ & $194(92.8)$ & \\
\hline \multicolumn{4}{|l|}{ Dyslipidemia } \\
\hline \multicolumn{4}{|l|}{ Yes } \\
\hline \multicolumn{4}{|l|}{ No } \\
\hline \multicolumn{4}{|l|}{ Retinopathy } \\
\hline \multicolumn{4}{|l|}{ Yes } \\
\hline \multicolumn{4}{|l|}{ No } \\
\hline Type of treatment & $47(24.6)$ & $32(15.3)$ & 0.000 \\
\hline Insulin only & $78(40.8)$ & $129(61.7)$ & \\
\hline Oral hypoglycemia agents only & $66(34.6)$ & $48(23.0)$ & \\
\hline Oral hypoglycemia agents \& Insulin & & & \\
\hline
\end{tabular}

About comorbid diseases/conditions $88.5 \%$ of hypertensive patients were having pain, $7.9 \%$ of patients with diabetic nephropathy were having pain, and $13.1 \%$ of patients with retinopathy were having pain as less than or more than 0.05 . Also, the pain was present in $24.6 \%, 40.8 \%$ and $34.6 \%$ in patients with insulin only, oral hypoglycemia agents only and oral hypoglycemia agents \& Insulin respectively, and this difference was found significant statistically $(P<0.05)$ as shown in Table 3. 
Regarding the quality of life of the participants who have DPNP, there were problems in mobility, self-care, usual activities, discomfort and anxiety /depression were reported in 1\%, 2.6\%, 29.8\%, $97.5 \%$, and $48.1 \%$ respectively, and this difference was found significant statistically $(P<0.05)$ as shown in (Table 4$)$.

The participants who have DPNP reported have problems in mobility, self-care, usual activities, discomfort, and anxiety /depression were reported $(r=0.606)$ at a moderate level $(50-69)$. Besides, the effect of pain on their quality of life by Kolmogorov-Smirnov test homogenate and we lead in our group was not homogenate were reported in $(D f=0.399)$, and this difference was found significant statistically $(P<0.05)$ as shown in Table 5.

Table 5: The Effects of DPNP on the Patients'Quality of Life of the Participants

\begin{tabular}{|lllc|}
\hline Variables & $\begin{array}{l}\text { The correlation coefficient of } \\
\text { QOL }\end{array}$ & $\begin{array}{l}\text { The correlation coefficient of } \\
\text { DPN }\end{array}$ & P-value \\
\hline Total QOL score & 1.000 & $0.606^{*}$ & 0.000 \\
\hline $\begin{array}{l}\text { Total DPNP } \\
\text { score }\end{array}$ & $0.606^{*}$ & 1.000 & 0.000 \\
\hline
\end{tabular}

*Spearman's rho correlation coefficient is significant at the 0.01 level (2-tailed)

\begin{tabular}{|c|c|c|c|c|c|}
\hline & \multicolumn{2}{|c|}{ Kolmogorov-Smirnov* } & \multicolumn{2}{|c|}{ Shapiro-Wilk } & \multirow[t]{2}{*}{ P-value } \\
\hline & Statistic & Df & Statistic & Df & \\
\hline Total DPNP score & 0.188 & 399 & 0.922 & 399 & 0.000 \\
\hline
\end{tabular}

*Lilliefors significance correlation

Table (6): Logistic regression analysis of significant factors associated with DPNP of the Participants 


\begin{tabular}{|lll|}
\hline P-value* & $\begin{array}{l}\text { 95\% Confidence Interval } \\
\text { (Lower }- \text { Upper })\end{array}$ & Variables \\
& & Gender \\
0.319 & $1^{*}$ & Male \\
& $0.728(0.390-1.358)$ & Female \\
& & HbA1c \\
0.015 & $1^{*}$ & Controlled $<7 \%$ \\
& $1.48(0.948-2.331)$ & Uncontrolled $\geq 7 \%$ \\
& & Body mass index $(\mathrm{BMI})(\mathrm{Kg} / \mathrm{cm} 2)$ \\
& $1 *$ & Normal \\
0.406 & $0.715(0.324-1.578)$ & Overweight \\
0.697 & $0.861(0.406-1.826)$ & Obese \\
& & Duration of diabetes \\
& $1 *$ & $<5$ years \\
0.738 & $1.088(0.663-1.784)$ & $5-11$ years \\
0.152 & $1.464(0.870-2.464)$ & $\geq 12$ years \\
\hline
\end{tabular}

(1) References group.

*P $\leq 0.05$

The binary logistic regression analysis was used to identify the impact of the demographic, clinical and laboratory variables on the DPNP using the entry system. If $p$-value $<0.05$ this indicated a significant influence of any demographic, clinical and laboratory variables on the DPNP. Besides, the odds ratios mentioned in the table indicate how likely given variables could contribute to the DPNP in adult patients (T2DM) with DPN. The result showed that revealed that subjects with uncontrolled diabetes were (1.48) times more likely to have DPNP compared to those subjects with controlled diabetes, and this difference was found significant statistically $(P<0.05)$ as shown in Table 6.

\section{Discussion}

Many studies showed the prevalence of DPNP ranging from 40 to 50\% [10]. The current study reported the overall prevalence of DPNP among adult patients (T2DM) with DPN as $47.8 \%$ which can be considered as high. The results of this study were contrary to the results of a recent study conducted in South Africa which found that the prevalence of DPNP was 30\% among patients with DPN [20]. Also, the results were not consistent with an observational study in England by Abbott et al. (2011), their results 
found that the prevalence of DPNP was 34.5\% among T2DM patients [21]. While these results were contrary to our findings, this might be attributed to the differences in the sample selected which included complicated patients with DPNP. Another possible explanation for this association could be related to the existence of different lifestyles among patients with DPNP including weight gain, and less physical activity.

However, in other studies where the prevalence of DPNP was less among patients diagnosed with T2DM, such as this was evident in a large national survey study conducted in France to estimate the prevalence of chronic pain with or without neuropathic characteristics [22]. The sample included 24,497 patients with diabetes and reported that 7,522 (31.7\%) of patients had pain in different intensity. However, neuropathic characteristics were reported by only 1,631 (6.9\%) of the assessed patients. In the region, a study was conducted in Saudi Arabia reported the prevalence of DPNP of 65.3\% among 1039 patients with T2DM and T1DM [23]; which is higher than the results found in the present study. Also, Jambart et at. (2011) assessed the prevalence of DPNP in 3989 patients with T2DM or T1DM in outpatient clinics across the Middle East using the DN4 instrument [24]. The results revealed that $53.7 \%$ of patients met the criteria for painful DPNP (Douleur Neuropathique-4 (DN4) scores $\geq 4$ ). This study showed a difference in the prevalence of DPNP among patients with diabetes mellitus. The involved countries in the study were Egypt $(n=783)$ Gulf States $(n=639)$ Jordan $(n=1194)$ Lebanon $(n=1373)$. The results showed that the prevalence in Jordan was 57.5\% which was less than Egypt (61.3\%); however, higher than the Gulf States and Lebanon (37.1\% and $53.9 \%$ respectively). This higher prevalence of the previous study from Jordan can be explained by the fact that this study included patients with T1DM and T2DM. However, patients with T1DM were 1.59 times more likely to have DPNP than patients with T2DM as less than or more than 0.05 . While our study included T2DM only. The difference in the reported prevalence from all over the world can be related to a different population of the studies and the different screening tools also the different scores for DN4 that are used to assess DPNP.

In this study, as shown in the results, participants were having different intensities of pain ranging from mild to moderate; however more than half of them experienced mild pain intensity. Also, the results showed that the most frequently reported symptoms were tingling, and burning, and the least reported symptoms were painful cold and itching.

Several studies evaluated the nature of pain among adult patients (T2DM) patients with DPNP. Burning, pins and needles and numbness were the most frequently reported symptoms of diabetic South African patients with DPNP [18, 20-22, 24-25]. In a French cross-sectional study that included 885 patients with T1DM and T2DM, numbness and burning were the most frequently reported symptoms with T2DM. While tingling and numbness were the most frequently reported symptoms among patients with T1DM [22]. In a nearby country (Saudi Arabia) burning, numbness and tingling were the most common symptoms of DPN in cases of establishing DPNP [23]. While burning, numbness, tingling and pins, and needles were the most frequently reported symptoms on the DN4 questions among 4097 patients with T2DM from several countries in the Middle East including Jordan [24]. 
According to pain intensity, $61 \%$ of patients had a pain of moderate-intensity in a cross-sectional study that included 1111 patients (776 T1DM, 344 T2DM), which was conducted in Brussels Belgium [26]. The investigators this trial used a visual analog scale (VAS) for assessment of pain intensity, while in our study $45 \%$ of patients with DPNP had moderate pain using the NRS measurement of pain intensity. While a study from the same region was conducted in French by (Bouhassiraet.al, 2013) using the NRS showed that $76.2 \%$ of patients are having a pain of moderate to severe intensity [25]. The difference in the reported for assessment of pain intensity can be related to a using different tools for assessment of pain intensity, the average pain intensity was moderate to severe in $71.4 \%$ of patients with DPNP in the united states the investigators in this study using Brief Pain Inventory (BPI-DPN) for assessment of pain intensity [27].

The effects of DPNP on the patients' QoL were assessed using the EQ5 questionnaire. The results of the study showed that most of the adult patients (T2DM) with DPN who have DPNP reported have a problem in mobility, self-care, usual activity, and anxiety. Relatively few studies have specifically assessed the impact of neuropathic pain on the health-related quality of life among patients with diabetes mellitus. These results of this study were concordant with those from other epidemiological studies, where adult patients (T2DM) with DPNP had significantly lower QoL than those without DPNP. For example, (Davies et al. 2006) assessed the impact of neuropathic pain in patients with T2DM on their quality of life. They found that patients who developed DPNP had poorer quality of life [28]. Similar results were found in a study conducted in Belgium by (Van Acker et al) on 1111 patients diagnosed with diabetes (767 T2DM and 344 T1DM). The results revealed that patients with DPNP were higher likely to report problems physical activities and mental alterations than those without DPNP, which may account for their lower QOL scores [26].

In a more recent study conducted in France to estimate the impact of DPNP on the QoL of 766 diabetic patients (38.7\% with T1DM, 44.8\% with T2DM), the results showed that DPNP was associated with disturbances in sleep, higher anxiety levels, and depression [25]. Another recent study that agrees with the results of our study was performed in South Africa. In this study, the results suggested that DPNP has a negative impact on QoL of 1036 patients with diabetes from 50 health care clinics [20]. To conclude, when comparing these results with the current study results, we found that there is a consensus that DPNP has a statistically significant negative effect on the QoL of the adult patients (T2DM) with DPN including both physical and mental status.

The results of this study showed that the participants' gender, $\mathrm{HbA} 1 \mathrm{c}, \mathrm{BMI}$ and duration of diabetes were predictors to the increases/develop incidence of DPNP in adult patients (T2DM) with DPN. The finding of this study showed the DPNP is related to uncontrolled diabetes. Our data showed that patients with an $\mathrm{HbA} 1 \mathrm{c} \geq 7 \%$ were 1.48 times more likely to have DPNP. Congruent to the results of this study is the finding of an across a sectional survey that conducted in the UK, to determine the severity of DPNP and it impacts on quality of life [28], which showed that the degree of neuropathy was associated with the degree of diabetes control; the OR for HbA1c was 1.28 ( $\mathrm{Cl}$ : 1.08-1.52; P-value $=0.004$ ). 


\section{Conclusions And Recommendations}

The prevalence of DPNP among adult patients (T2DM) with DPN in this study was $47.8 \%$. Our data showed that patients with an $\mathrm{HbA} 1 \mathrm{c} \geq 7 \%$ were significantly associated with an increased prevalence of DPNP in adult patients (T2DM) with DPN. Tingling and burning are the highest reported symptoms of DPNP. A problem in mobility, self-care, usual activity, and anxiety was found in adult patients (T2DM) having DPNP.

Furthermore, DPNP is common, difficult to manage complications of diabetes [30]. Identifying patients with DPNP will eventually lead to a significant improvement in the management of these health problems and reduction in its adverse consequences, thereby highlighting the need for improved awareness, health education, early detection, and intervention are important measures for those patients. Also, more attention is needed to prevent late-onset DPNP complications, even in asymptomatic patients. Old patients with long-standing DM should be screened continuously for DPNP. Moreover, the initial measures to prevent DPNP and improves the quality of life include glycemic control and implementation with modification of lifestyle and behavioral changes such as appropriate diet, exercise, and regularly visit treating physicians $[20,25,28,31]$. Moreover, as a positive association between DPNP and quality of life in adult patients (T2DM) with DPNP exists, it is recommended that all healthcare parties should be knowledgeable of the importance of the quality of life and DPNP for those patients. Consultations with the patient on this topic should be made. After research, we and all healthcare parties decided to publish informative booklets and distribute them to diabetic patients.

\section{Limitations}

However, some limitations may be recognized in relation to the conduction of this study. Although the focus of this study was to assess the prevalence of PDNP among adult patients (T2DM) with DPN, the data collection lacks identifying if patients were taking pain pharmacological and non-pharmacological therapies. Future research is recommended to include patients from different health care sectors in Jordan and other health care facilities.

\section{Declarations}

Ethical Approval Committee: Available. Ethics committee approval was received for this study from the Jordanian Ministry of Health Ethical Board (No: 9911).

\section{Authors' contributions}

JAA: Study design, data collection, statistical analysis, and manuscript preparation.Responsible and accountable for the accuracy or integrity of the work

NB:Review, edit and final approval of the manuscript. 
HB: Study design, statistical analysis and review the manuscript.

\section{Acknowledgment: No}

Conflicts of interest:There are no conflicts of interest.

\section{References}

1. Wu Y, Ding Y, Tanaka Y, Zhang W. Risk factors contributing to type 2 diabetes and recent advances in the treatment and prevention. International journal of medical sciences. 2014;11(11):1185. doi:10.7150/ijms.10001.

2. International Diabetes Federation (IDF). 2013: IDF Diabetes Atlas 6th Editon. Brussels, Belgiun. Retrived. No (22). From: http://www.idf.org/diabetessatlas.

3. Ajlouni K, Kader S, Batieha A, Ajlouni H, El-Kateeb M. An increase in prevalence of diabetes mellitus in Jordan over 10 years. Journal of Diabetes its Complications. 2009;22(5):317-24. doi:10.1016/j.jdiacomp.2007.01.004. Epub 2008 Apr 16.

4. Alqurashi A, Aljabri S, Bokhari A. Prevalence of diabetes mellitus in a Saudi community. Ann Saudi Med. 2011;31(1):19. doi:10.4103/0256-4947.75773.

5. 10.1002/(SICl)1096-9136(199806)15:6<508 Boulton, A. J. M., Gries, F. A., \& Jervell, J. A. (1998). Guidelines for the diagnosis and outpatient management of diabetic peripheral neuropathy. Diabetic Medicine, 15(6), 508-514 I). DOI: 10.1002/(SICI)1096-9136(199806)15:6<508: AID-DIA613 > 3.0.CO;2-L.

6. Cade WT. Diabetes-related microvascular and macrovascular diseases in the physical therapy setting. Physical therapy. 2008;88(11):1322-35. doi:10.2522/ptj.20080008.

7. Chawla A, Chawla R, Jaggi S. Microvasular and macrovascular complications in diabetes mellitus: distinct or continuum? Indian journal of endocrinology metabolism. 2016;20(4):546. DOI:10.4103/2230-8210.183480.

8. Barrett, E. J., Liu, Z., Khamaisi, M., King, G. L., Klein, R., Klein, B. E., ... Vinik,A. I. (2017). Diabetic microvascular disease: an endocrine society scientific statement. The Journal of Clinical Endocrinology \& Metabolism, 102(12), 4343-4410. doi: 10.1210/jc.2017-01922.

9. Tesfaye S, Kempler P. Painful diabetic neuropathy. Diabetologia. 2005;48(5):805-7. DOI 10.1007/s00125-005-1721-7.

10. $10.1016 / \mathrm{s} 0025-6196(11) 61474-2$

Argoff C, Cole B, Fishbain D, Irving G. (2006). Diabetic peripheral neuropathic pain: clinical and quality-of-life issues. In Mayo Clinic Proceedings (Vol. 81, No. 4, pp. S3-S11). Elsevier. DOI: 10.1016/s0025-6196(11)61474-2.

11. Veves A, Backonja M, Malik RA. Painful diabetic neuropathy: epidemiology, natural history, early diagnosis, and treatment options. Pain medicine. 2008;9(6):660-74. https://doi.org/10.1111/j.15264637.2007.00347.x. 
12. Vinik Al. Management of neuropathy and foot problems in diabetic patients. Clinical Cornerstone. 2003;5(2):38-55. DOI:10.1016/s1098-3597(03)90017-2.

13. Spollett GR. Diabetic neuropathies: diagnosis and treatment. Nursing Clinics. 2006;41(4):697-717. DOI:10.1016/j.cnur.2006.07.012.

14. American pain society (APS). (2003). Principles of analgesic use in the treatment of acute pain and cancer pain (5th ed). Glenview IL Author.

15. Reed C, Hong J, Novick D, Lenox-Smith A, Happich M. Incidence of diabetic peripheral neuropathic pain in primary care-a retrospective cohort study using the United Kingdom General Practice Research Database. Pragmatic observational research. 2013;4:27. doi:10.2147/POR.S49746.

16. Bouhassira, D., Attal, N., Alchaar, H., Boureau, F., Brochet, B., Bruxelle, J., ...Vicaut, E. (2005). Comparison of pain syndromes associated with nervous or somatic lesions and development of a new neuropathic pain diagnostic questionnaire (DN4). Pain, 114(1), 29-36. DOI: 10.1016/j.pain.2004.12.010.

17. Terkawi, A. S., Abolkhair, A., Didier, B., Alzhahrani, T., Alsohaibani, M., Terkawi,Y. S., ... Tsang, S. (2017). Development and validation of Arabic version of the douleur neuropathique 4 questionnaire. Saudi journal of anaesthesia, 11(Suppl 1), S31. DOI: 10.4103/sja.SJA_97_17 PMID: 28616002. PMCID: PMC5463565.

18. Group TE. EuroQol-a new facility for the measurement of health-related quality of life. Health policy. 1990;16(3):199-208. DOI:10.1016/0168-8510(90)90421-9.

19. Türk Nöroloji. Derneği @NOROLOJI.1992. 17th NÖROPATiK AĞRI SEMPOZYUMU, 28th Şubat-1st Mart, 2020. Kibris, Elexus ve Kongre Merkezi, p. 9.

20. Jacovides A, Bogoshi M, Distiller LA, Mahgoub EY, Omar MK, Tarek IA, Wajsbrot DB. (2014). An epidemiological study to assess the prevalence of diabetic peripheral neuropathic pain among adults with diabetes attending private and institutional outpatient clinics in South Africa. J Int Med Res, 0300060514525759. DOI:10.1177/0300060514525759.

21. Abbott A, Malik A, van Ross R, Kulkarni J, Boulton J. Prevalence and characteristics of painful diabetic neuropathy in a large community-based diabetic population in the UK. Diabetes Care. 2011;34(10):2220-4. doi:10.2337/dc11-1108. Epub 2011 Aug 18.

22. Bouhassira D, Lantéri-Minet $M$, Attal N, Laurent B, Touboul C. Prevalence of chronic pain with neuropathic characteristics in the general population. Pain. 2008;136(3):380-7.

DOI:10.1016/j.pain.2007.08.013.

23. Halawa MR, Karawagh A, Zeidan A, Mahmoud AEDH, Sakr M, Hegazy A. Prevalence of painful diabetic peripheral neuropathy among patients suffering from diabetes mellitus in Saudi Arabia. Current Medical Research Opinion. 2009;26(2):337-43. DOI:10.1185/03007990903471940.

24. Jambart, S., Ammache, Z., Haddad, F., Younes, A., Hassoun, A., Abdalla, K., ... Youseif,E. (2011). Prevalence of painful diabetic peripheral neuropathy among patients with diabetes mellitus in the Middle East region. Journal of International Medical Research, 39(2), 366-377. DOI: 10.1177/147323001103900204. 
25. 10.1371/journal.pone.0074195

Bouhassira D, Letanoux M, Hartemann A. (2013). Chronic pain with neuropathic characteristics in diabetic patients: a French cross-sectional study. PloS one, 8(9), e74195. doi: 10.1371/journal.pone.0074195. eCollection 2013.

26. Van Acker, K., Bouhassira, D., De Bacquer, D., Weiss, S., Matthys, K., Raemen, H.,... Colin, I. M. (2009). Prevalence and impact on quality of life of peripheral neuropathy with or without neuropathic pain in type 1 and type 2 diabetic patients attending hospital outpatients' clinics. Diabetes \& metabolism, 35(3), 206-213. https://doi.org/10.1016/j.diabet.2008.11.004.

27. Gore M, Brandenburg NA, Dukes E, Hoffman DL, Tai KS, Stacey B. Pain severity in diabetic peripheral neuropathy is associated with patient functioning, symptom levels of anxiety and depression, and sleep. J Pain Symptom Manag. 2005;30(4):374-85. DOI:10.1016/j.jpainsymman.2005.04.009. DOI: 10.1016/j.jpainsymman.2005.04.009.

28. Davies M, Brophy S, Williams R, Taylor A. The prevalence, severity, and impact of painful diabetic peripheral neuropathy in type 2 diabetes. Diabetes Care. 2006;29(7):1518-22. DOI:10.2337/dc052228.

29. Diabetes Control and Complications Trial Research Group. The effect of intensive diabetes therapy on measures of autonomic nervous system function in the Diabetes Control and Complications Trial (DCCT). Diabetologia. 1998;41(4):416-23. https://doi.org/10.1007/s001250050924.

30. Larme AC, Pugh JA. Attitudes of primary care providers toward diabetes: barriers to guideline implementation. Diabetes Care. 1998;21(9):1391-6. DOI:10.2337/diacare.21.9.1391.

31. Reed C, Hong J, Novick D, Lenox-Smith A, Happich M. (2013). Incidence of diabetic peripheral neuropathic pain in primary care-a retrospective cohort study using the United Kingdom General Practice Research Database. Pragmatic Observational Research, 4. DOI https://doi.org/10.2147/POR.S49746. 